\title{
POLÍTICAS PÚBLICAS DE SAÚDE: IMPACTOS MUNICIPAIS DECORRENTES DA SOLIDARIEDADE PASSIVA IRRESTRITA IMPOSTA PELO PODER JUDICIÁRIO AOS ENTES DA FEDERAÇÃO
}

\author{
PUBLIC HEALTH POLICIES: MUNICIPAL IMPACTS ARISING FROM \\ UNRESTRICTED PASSIVE SOLIDARITY IMPOSED BY JUDICIAL \\ POWER ON FEDERATION ENTITIES
}

Thaís Assunção Nunes ${ }^{1}$

\begin{abstract}
RESUMO: O presente artigo tem como intuito investigar acerca dos impactos ocasionados aos municípios, especialmente os de pequeno e médio porte, decorrentes das decisões judiciais que, de forma geral, impõem a solidariedade passiva irrestrita entre a municipalidade e os demais entes da federação. Para tanto, utilizando como referencial teórico o art. 23 da Constituição Federal, explanamos sobre o direito à saúde e sua alocação como direito fundamental. Discorremos sobre a organização da saúde pública, bem como a fragilização pela qual passa o federalismo cooperativo, tendo como reflexo a deplorável prestação de serviços à população, que por sua vez busca o Poder Judiciário para a obtenção do mínimo exitencial em matéria de saúde. Tratamos das decisões do Poder Judiciário aplicando indistintamente os ditames da Constituição Federal de 1988, que instituiu a competência comum na prestação dos serviços públicos de saúde, entendendo haver responsabilidade solidária entre União, Estados, Distrito Federal e Municípios, em detrimento de normas legais e infra legais que preveem a repartição de competências na prestação desses serviços. A partir de tais estudos, chegou-se a conclusão que tal ativismo judicial gera impactos sociopolíticos nos municípios de pequeno e médio porte, visto que essas municipalidades não são detentoras de recursos financeiros suficientes para abarcar todas as demandas, devendo obediência ao princípio da reserva do possível.
\end{abstract}

PALAVRAS CHAVE: Saúde Pública, Cidades, Poder Judiciário, Ativismo Judicial, Reserva do Possível.

\footnotetext{
1 Especialista em Direito Civil pela Faculdade Anhanguera, Mestranda em Direito Constitucional Econômico pelo Centro Universitário Alves Faria, Docente do Curso de Direito do Centro Universitário Unicathedral, Procuradora Municipal de Barra do Garças-MT.
} 
ABSTRACT: This article aims to investigate the impacts caused to municipalities, especially small and medium-sized ones, resulting from judicial decisions that, in general, impose unrestricted passive solidarity between the municipality and the other entities of the federation. To do so, using art. 23 of the Federal Constitution, we explain about the right to health and its allocation as a fundamental right. We talked about the organization of public health, as well as the fragility that cooperative federalism goes through, reflecting the deplorable provision of services to the population, which in turn seeks the Judiciary to obtain the minimum existential in health matters. We deal with the decisions of the Judiciary Power applying the dictates of the 1988 Federal Constitution, which established common competence in the provision of public health services, understanding that there is joint and several liability between the Union, States, Federal District and Municipalities, to the detriment of legal and infra rules provisions that provide for the division of powers in the provision of these services. From these studies, it was concluded that such judicial activism generates socio-political impacts in small and medium-sized municipalities, since these municipalities do not have sufficient financial resources to cover all demands, and must obey the principle of possible.

KEYWORDS: Public Health, Cities, Judiciary, Judicial Activism, Reserve of the Possible. 


\section{INTRODUÇÃO}

A sáude foi retratada pelo constituinte originário como um direito fundamental social. Para além de sua abrangência comunitária, a saúde se perfaz como direito individual advindo daí sua natureza híbrida: subjetiva e pública, constituindo tanto em um direito de cada cidadão quanto em um dever do Estado para com toda a coletividade.

Enquanto direito positivo, a saúde é assegurada a todos e dever do Estado, a ser garantida mediante a realização de políticas públicas, com acesso igualitário e universal.

Organizacionalmente, a saúde pública é estruturada por um agrupamento uno, denominado Sistema Único de Saúde - SUS, composto por uma rede regionalizada, hierarquizada e descentralizada - diretrizes do federalismo cooperativo -, financiada com recursos do orçamento da seguridade social, da União, dos Estados, do Distrito Federal e dos Municípios, compreendendo direção única em cada esfera do governo, com competências distribuídas para cada um dos três gestores do SUS, e divisão das responsabilidades pelas ações e serviços.

Entretanto, a crise desse federalismo cooperativo é evidente: a ausência de medicamentos, a escassez de procedimentos, a demora no atendimento, a má remuneração dos profissionais da saúde, entre outros, são constantes. Os fatores principais para tal cenário decorrem, entre outros, da competição de recursos entre os entes federativos, da disparidade entre os municípios, principalmente no que diz respeito às capacidades de gestão e de recursos de acolhimento à saúde e das crises fiscais a que as administrações estaduais estão sujeitas, na maioria das vezes em razão da impontualidade no repasse de recursos por parte da União, com o consequente abandono da agenda da saúde por parte dos entes hierarquicamente subsequentes. 
Por tudo isso, a plenitude de acesso à saúde aos cidadãos está longe de ser indubitável. O poder público, principalmente os municípios de pequeno e médio porte, são incapazes de prestar um efetivo serviço de saúde à população.

Esse déficit pode ser constatado pelo exponencial crescimento de demandas judiciais que têm por objeto a prestação de serviços de saúde e/ou o fornecimento de medicamentos, negados aos cidadãos pela via administrativa ou que sequer foram solicitados junto ao ente público. Isto ocorre, nesse último caso, porque o indivíduo, já sabedor do desamparo do Poder Executivo, procura diretamente o Poder Judiciário para ver atendidos seus anseios.

O Poder Judiciário, assim, tem sido protagonista em garantir o acesso aos serviços de saúde à população, atuando proativamente no sentido de suprir as dificuldades administrativas e dar efetividade a essa garantia constitucional à população. Contudo, a cúpula do Poder Judiciário, o Supremo Tribunal Federal STF, ainda não se pronunciou, de forma específica e definitiva, quanto à validade das normas legais e infra legais de distribuição de competência e atribuições dos entes da federação no que se refere às ações e serviços de saúde, razão pela qual os juízes, em sua maioria, vem aplicando de forma irrestrita o preceito de solidariedade passiva instituído no artigo 23, inciso II, da Constituição Federal.

As decisões judiciais atribuindo tal responsabilidade solidária, na qual é imposta idêntica responsabilidade às três esferas de governo no acesso à saúde, têm agravado ainda mais os problemas de gestão, mormente dos municípios menores, ocasionando um impacto deslocativo em seus orçamentos, sendo obrigados a desviar recursos para ações não planejadas, com sérios riscos de se atender uma demanda judicial individual e deixar de contemplar as necessidades da população local.

Além disso, a solidariedade ilimitada, ordenada pelos doutos juízos, acaba por ferir o Princípio da Eficiência, norteador da administração pública, uma vez que, as realizações das mesmas tarefas são incumbidas, concomitantemente, aos organismos federais, estaduais e municipais, causando uma verdadeira desordenação do serviço prestado, com a multiplicidade de meios para idêntico fim, com impactos, por óbvio, absolutamente negativos na gestão pública municipal. 
Ainda, deve-se ter em mente que o município deve obediência ao princípio da reserva do possível, que subordina a prestação dos serviços à existência de recursos públicos para tal, vinculando a efetivação dos direitos sociais às possibilidades financeiras do ente.

\section{O DIREITO À SAÚDE NO ORDENAMENTO JURÍDICO BRASILEIRO}

No ordenamento pátrio brasileiro, a saúde tem papel de destaque, estando definida na Constituição Federal de 1988 como um dos direitos fundamentais sociais do cidadão. Tal direito, de acordo com a previsão constitucional, é dever do Estado como um todo.

O direito à saúde é tratado expressamente em vários dispositivos da Constituição brasileira, entre eles o art. $6^{\circ}$, art. $7^{\circ}$, incisos IV e XXII, art. 23, art. 24, inciso XII, art. 34, inciso VII, alínea "e" e art. 35, inciso III. Apresenta, ainda, uma seção específica inserida no capítulo destinado à Seguridade Social (arts. 196 e seguintes).

Entre os principais decisórios constitucionais, o art. $6^{\circ}$ dispõe ser a saúde um direito social ao lado da educação, alimentação, trabalho, moradia, transporte, lazer, segurança, previdência social, proteção à maternidade e à infância e assistência aos desamparados.

No artigo 23 é imposta a competência comum da União, dos Estados, do Distrito Federal e dos Municípios para cuidar da saúde e assistência pública, competindo à União, aos Estados e ao Distrito Federal legislar concorrentemente sobre previdência social, proteção e defesa da saúde, nos termos do inciso XII do art. 24.

A alínea "e" do inciso VII do artigo 34 da CF garante a não intervenção da União nos Estados ou Distrito Federal, exceto para assegurar a aplicação do mínimo exigido da receita, resultante de impostos estaduais, compreendida a proveniente de transferências, na manutenção e desenvolvimento do ensino e nas ações e serviços públicos de saúde. Do mesmo modo, o Estado não intervirá em seus Municípios, 
nem a União nos Municípios localizados em Território Federal, exceto quando não tiver sido aplicado o mínimo exigido da receita municipal na manutenção e desenvolvimento do ensino e nas ações e serviços públicos de saúde.

Dentro do capítulo destinado à Seguridade Social, a Constituição Federal entendeu ser a saúde direito de todos e dever do Estado, garantido mediante políticas sociais e econômicas que visem à redução do risco de doença e de outros agravos e ao acesso universal e igualitário às ações e serviços para sua promoção, proteção e recuperação, considerando como de relevância pública as ações e serviços de saúde, cabendo ao Poder Público dispor, nos termos da lei, sobre sua regulamentação, fiscalização e controle, devendo sua execução ser feita diretamente ou através de terceiros e, também, por pessoa física ou jurídica de direito privado.

Neste sentido, analisando o detalhamento constitucional do direito à saúde, Ledur (2009, p.89) conclui que se trata de um direito humano fundamental que exige uma prestação positiva do "Estado" e da sociedade, a ser inserido nas políticas públicas em igualdade de direito a todos, independentes de classe social, raça, cor ou credo.

Silva (2007, p. 767) corrobora esse ensinamento ao explicitar que a igualdade da saúde visa o atendimento a todos, "independentemente de sua situação econômica, sob pena de não ter muito valor sua consignação em normas constitucionais".

No mesmo sentido, o nobre jurista Sarlet (2012, p. 215) salienta que a Constituição Federal atribui a titularidade do direito à saúde a toda e qualquer pessoa, inclusive ao estrangeiro. Ainda, na seara do acesso igualitário e universal da saúde, os estudos do conceituado o Promotor de Justiça de Minas Gerais, Assis (2013, p. 87), empenhado profissionalmente pela melhoria da saúde pública, demonstra que "eventual interpretação judicial restritiva do princípio constitucional da universalidade do acesso às ações e serviços de saúde é inconstitucional”. 


\section{DA FORMA DE PRESTAÇÃO DOS SERVIÇOS PÚBLICOS DE SAÚDE}

Buscando atender aos anseios da população quanto ao direito fundamental à saúde, a Constituição Federal de 1988 procurou estabelecer uma estrutura na qual essas necessidades pudessem ser identificadas e tratadas, de forma rápida e eficaz, contrapondo-se aos ditames antecedentes onde somente os contribuintes do sistema eram beneficiados.

Avaliadas a densidade demográfica e a extensão territorial brasileira, verificou-se a necessidade da criação de um sistema descentralizado, hierarquizado e regionalizado que pudesse, em razão da proximidade com os cidadãos, melhor atendê-los.

Para alcançar esse objetivo, o constituinte nacional determinou, no art. 198 da $\mathrm{CF}$, que as ações e serviços públicos de saúde devem integrar uma rede regionalizada e hierarquizada, constituindo um sistema único, organizado de acordo com as seguintes diretrizes: a) descentralização, com direção única em cada esfera de governo; b) atendimento integral, com prioridade para as atividades preventivas, sem prejuízo dos serviços assistenciais; c) participação da comunidade.

Ademais, o sistema único de saúde será financiado, nos termos do art. 195, com recursos do orçamento da seguridade social, da União, dos Estados, do Distrito Federal e dos Municípios, além de outras fontes.

No ano de 1990 foi editada a Lei 8.080 , de 19 de setembro daquele ano, dispondo sobre as condições para a promoção, proteção e recuperação da saúde, bem como a organização e o funcionamento dos serviços correspondentes.

Saliente-se que o Sistema Único de Saúde (SUS) é constituido pelo conjunto de ações e serviços de saúde, fornecidos por órgãos e instituições públicas federais, estaduais e municipais, da Administração direta e indireta e das fundações mantidas pelo Poder Público, prestando-se a promovê-la, dando prioridade às ações preventivas e informando à população sobre seus direitos e riscos.

Atendendo a esse preceito, os Tribunais Superiores têm decidido que a integralidade do atendimento à saúde deve priorizar as atividades preventivas 
coletivas, mas sem excluir os tratamentos individuais, de natureza preventiva ou curativa.

Nesse sentido, acentuou o Ministro Celso Mello (BRASIL, 2007):

O caráter programático da regra inscrita no art. 196 da Carta Política, que tem por destinatários todos os entes políticos que compõem, no plano institucional, a organização federativa do Estado brasileiro não pode converter-se em promessa constitucional inconsequente, sob pena de o Poder Público, fraudando justas expectativas nele depositadas pela coletividade, substituir, de maneira ilegítima, o cumprimento de seu impostergável dever, por um gesto irresponsável de infidelidade governamental ao que determina a própria Lei Fundamental do Estado. (STF - RE-AGR No 393175/RS, $2^{\mathrm{a}}$ TURMA, REL. MIN. CELSO DE MELLO, DJ 02-02-2007).

O Ministro Gilmar Mendes, do Supremo Tribunal Federal, salientando sobre a integralidade do acesso à saúde e acerca da prevalência do tratamento oferecido pelo Sistema Único de Saúde, asseverou em seu voto, ao julgar a Suspensão de Tutela Antecipada - STA/CE $n^{\circ} 175$, que de modo geral, deverá ser privilegiado o tratamento fornecido pelo SUS em detrimento de opção diversa escolhida pelo paciente, sempre que não for comprovada a ineficácia ou a impropriedade da política de saúde existente.

Muitas são, portanto, as vantagens de sistemas descentralizados como o SUS, havendo diversos autores que explanam acerca das exitosas experiências de cooperação regional nele pautadas: Mendes (1993), Ribeiro e Costa (2000, p. 173220), Neves e Ribeiro (2006, p. 2.207-2.217), Machado e Andrade (2014, p. 695720).

No entanto, mesmo com todas as teóricas vantagens de estruturas como o Sistema Único de Saúde, seu colapso se mostra real. 


\section{CRISE DO FEDERALISMO COOPERATIVO E A IMPOSIÇÃO JUDICIAL DA SOLIDARIEDADE PASSIVA IRRESTRITA ENTRE OS MUNICÍPIOS E OS DEMAIS ENTES DA FEDERAÇÃO}

Apesar dos conjecturais benefícios do sistema hierárquico e descentralizado de prestação dos serviços públicos de saúde, por fatores diversos o federalismo cooperativo se encontra em desequilíbrio, não estando tais serviços sendo prestados a contento à população, razão pela qual o número de ações judiciais em desfavor dos entes públicos, tendo por objeto o fornecimento de medicamentos e/ou realização de tratamentos, é exponencialmente crescente. Os motivos são diversos.

As crises fiscais constantes, pelas quais atravessam os governos estaduais, culminam, em uma volumosa contagem de casos, no abandono das agendas de saúde, ausentando esses entes de repassarem verbas destinadas a essa finalidade para os municípios. De outro turno, não há entre as administrações municipais uma paridade nas capacidades fiscais, de governo e de recursos relativos à saúde. Por esta razão, é ferrenha a competição por esses recursos.

Ademais, os colegiados de gestão regionais, responsáveis por considerável parcela das pactuações de políticas públicas de saúde, não se mostram efetivos, na maior parte das vezes como consequencia de suas constantes alterações, tanto estruturais quanto de denominação, oriundas de sucessivas portarias ministeriais e decretos presidenciais, o que impede a estipulação de regras seguras e robustas.

Ratificando essas assertivas, alguns autores apontam como causa relevante para a ausência de efetividade do cooperativismo federativo a falta de políticas de desenvolvimento regional, que aparece em diversos estudos, associada, por vezes, também à mencionada evidência de desigualdades de caráter socioeconômico: Arretche e Marques, (2002, p.455-479), Travassos, Oliveira e Viacava (2006, p. 975986), Viana, Lima e Ferreira (2010, p. 2.317-2.326), Gadelha et al. (2011, p. 3.0033.016), Viacava e Bellido (2016, p. 351-370), Piola, França e Nunes (2016, p. 411421). 
Também, outros estudiosos trazem ao debate político pontuações ligadas ao federalismo fiscal e que evidenciam seus efeitos nas disparidades regionais e como oportunidade de reforma tributária equitativa, entre eles Dain et al. (2001, p. 233288) e Lima (2007, p. 511-522)).

Impende destacar que as vantagens da descentralização radical de políticas, como as de saúde, em países como o Brasil - com elevado índice populacional, grande extensão de área e enormes desigualdades regionais -, ainda estão por ser efetivamente demonstradas.

Em razão deste e de outros fatos secundários, resta evidente que o Estado brasileiro ainda está longe de assegurar a plenitude de acesso e tratamento integral à saúde, tendo transferido ao Poder Judiciário o protagonismo em garantir o acesso aos serviços de saúde da população.

Norteando tal constatação, observa-se um elevado número de lides relativas à prestação de serviços públicos de saúde.

No entanto, o tratamento dado pelo Poder Judiciário na maioria dessas demandas, reconhece que a responsabilidade pela prestação dos serviços de saúde pelos entes federativos deve ser solidária, acaba por acarretar diversas incongruências jurídicas, tanto processuais quanto materiais.

$\mathrm{Na}$ seara estritamente processual, por exemplo, diante de tal crença jurídica referente à solidariedade, abre-se a possibilidade ao demandante, por sua livre escolha, de propor ações idênticas, ora em desfavor da União, ora em face do Estado ou do Município, ou por vezes contra todos simultaneamente, junto à Justiça Federal ou Estadual, sem que seja possível detectar a ocorrência de litispendência, conexão, coisa julgada ou duplo deferimento do pedido, em prejuízo de todo o sistema público de saúde.

No que lhes concernem, os juízos estaduais ou federais podem declarar-se competentes ou incompetentes para a análise do pleito, revestindo tais incidentes de grande gravidade no campo da saúde, vez que a demora na resolução desse incidente processual pode acarretar o perecimento do direito pleiteado, respondendo os requerentes, em certos casos, com a própria vida.

Nesse ponto reside, em domínio processual, a necessidade de se delimitar parâmetros objetivos no que se refere às atribuições, competências e 
responsabilidades de cada um dos entes políticos que compõem o sistema descentralizado prestador dos serviços de saúde, para que se possa, com nitidez, abalizar em desfavor de qual ente se deve impetrar o pedido e, consequentemente, qual juízo apreciará a contenda.

Outrossim, incongruências materiais igualmente são evidentes, visto que ao exararem suas decisões o Poder Judiciário pode estar favorecendo determinados grupos e prejudicando outros, acabando por retirar recursos destinados ao atendimento da população em geral para o acolhimento de um caso específico.

Saliente-se o posicionamento do douto Ministro Eros Grau (BRASIL, 2006), no julgamento da ADI n³.305:

A máxima da igualdade é violada quando para a diferenciação legal ou para o tratamento legal igual não seja possível encontrar uma razão adequada que surja da natureza da coisa ou quem de alguma forma, seja compreensível, isto é, quando a disposição tenha de ser qualificada de arbitrária.

Confirmando o entendimento anteriormente esposado, insta mencionar a decisão da Presidência da Suprema Corte no Pedido de Suspensão de Tutela Antecipada $n^{\circ} 91$ (2007) que suspendeu os efeitos da decisão proferida pelo Egrégio Tribunal de Justiça de Alagoas que havia comtemplado a um cidadão tratamento de saúde em desacordo com a política definida pelo Ministério Nacional de Saúde, em detrimento da sociedade:

Entendo que a norma do art. 196 da Constituição da República, que assegurou o direito à saúde, refere-se em princípio, à efetivação de políticas públicas que alcancem a população como um todo, assegurando-lhe acesso universal e igualitário, e não a situações individualizadas. A responsabilidade do Estado em fornecer os recursos necessários à reabilitação da saúde de seus cidadãos não pode vir a inviabilizar o sistema público de saúde. No presente caso, ao se conceder os efeitos da antecipação da tutela para determinar que o Estado forneça os medicamentos relacionados "(...) e outros medicamentos necessários para o tratamento (...)" (fl. 26) dos associados, está-se diminuindo a possibilidade de serem oferecidos serviços de saúde básicos ao restante da coletividade. 
De suma importância também se mostra a análise do impacto sociopolítico, especificamente o financeiro, que tais decisões judiciais acarretam aos cofres dos pequenos e médios municípios.

Isso porque, a irrestrita solidariedade dos entes da Federação na prestação dos serviços de saúde termina por dificultar, notadamente, a sobrevivência financeira das municipalidades de baixo porte, considerada a sua fragilidade orçamentária em relação ao seu respectivo Estado e à União.

No entendimento do ilustre Ministro Luís Roberto Barroso (BRASIL, 2009), as decisões judiciais neste sentido acabam por agravar as dificuldades de gestão, sobretudo dos Municípios menores, porque sofrendo um impacto deslocativo no orçamento são obrigados a desviar recursos para ações não planejadas, sem atentar que isso acarreta "ineficiência na prestação dos serviços de saúde, com a mobilização de recursos federais, estaduais e municipais para realizar as mesmas tarefas".

A ausência de individualização das atribuições repercute, como já dito, na esfera administrativo-orçamentária das entidades, irradiando impactos sociais e econômicos que transcendem a própria demanda, eventualmente tornando inviável a gestão administrativa, sobretudo dos municípios pequenos.

\section{O MÍNIMO EXISTENCIAL E A RESERVA DO POSSÍVEL}

O ordenamento pátrio, como já dito, buscou resguardar a prevenção e o tratamento de doenças acometidas pelos cidadãos brasileiros. Para tanto, o Poder Público deve implementar políticas públicas voltadas à saúde de cada indivíduo e da coletividade.

Essa salvaguarda refere-se ao denominado "mínimo existencial", que diz respeito às condições básicas de vida digna, sendo considerado, portanto, inerente a todos os seres humanos. 
O chamado mínimo existencial é um direito fundamental previsto na Constituição Federal e, por ser considerado intrínseco à raça humana, independe de lei para sua efetivação.

Sendo um direito fundamental, cabe ao Estado garantir a aplicação eficaz do mínimo existencial, que abrange os direitos socioeconômicos e culturais.

Todavia, ao longo dos anos o rol dos direitos fundamentais teve crescimento vertiginoso, e, na contramão dessa ascensão, os recursos estatais tiveram um decréscimo na mesma proporção. Deste modo, originou-se a reserva do possível: a efetivação dos direitos fundamentais deve ser limitada considerando a escassez de recursos financeiros para tal.

Mesmo decorrente do Estado, o dever de garantir aos cidadãos o mínimo existencial, não se pode olvidar que, apesar dessa obrigatoriedade imposta pela legislação, todas as receitas e despesas públicas estão limitadas por lei, de modo que os entes não podem realizar, indiscriminadamente, investimentos para os quais não haja recursos satisfatórios.

Assim, embora o direito à saúde se consubstancie como um direito social, sua efetivação encontra óbice na insuficiência de recursos financeiros e na necessidade que o administrador tem de selecionar as prioridades que melhor atendam ao interesse público.

Isto quer dizer que, apesar de todos terem direito à saúde, deve-se ter em conta que o administrador não pode prestar serviços a apenas um indivíduo e/ou grupo de indivíduos em detrimento de toda a coletividade. A prestação deve ser realizada tendo por fundamento os princípios da proporcionalidade e da razoabilidade.

Nesse diapasão, surge para o gestor público a necessidade de fazer escolhas. Tais escolhas, como já dito, devem ser pautadas no princípio da reserva do possível, onde a necessidade-possibilidade devem ser aferidas. Ressalte-se que o mínimo existencial está condicionado à avaliação do binômio necessidadecapacidade tanto do cidadão quanto do Poder Público.

Nos municípios de pequeno e médio porte não se afigura viável, por exemplo, a manutenção de tratamento de altíssimo custo e sem perspectiva de efetividade 
para o paciente, restando evidente que as decisões judiciais impondo gastos municipais nesse sentido ferem o princípio da reserva do possível.

É necessário que, no caso concreto, para que a reserva do possível seja preservada, estejam presentes a distributividade dos recursos, o número de cidadãos atingidos e a efetividade do serviço.

Lado outro, o princípio da reserva do possível não deve ser banalizado para que não se acentue a já existente má prestação de serviços de saúde, bem como seja salvaguardado o mínimo existencial de cada indivíduo.

\section{CONSIDERAÇÕES FINAIS}

O presente estudo teve como principal objetivo discorrer acerca dos impactos sociopolíticos, financeiros e jurídicos oriundos da solidariedade passiva irrestrita imposta pelo Poder Judiciário, concomitantemente, aos municípios e aos demais entes da federação, desconsiderando a estrutura existente para a prestação de serviços de saúde.

Para tanto, foi utilizado como referêncial teórico o art. 23 da Constituição Federal que assevera ser comum e concorrente a competência da União, dos Estados, do Distrito Federal e dos Municípios para cuidar da saúde e assistência pública.

Inicialmente, alocamos o direito à saúde no ordenamento jurídico brasileiro, onde pudemos concluir que, conforme o disposto no art. 196 da Constituição Federal, a sáude é um direito fundamental social intrínseco à todos os seres humanos, devendo sua efetivação ser assegurada pelo Poder Público.

Buscando implementar o direito fundamental social à saúde, considerando a densidade demográfica e a extensão territorial brasileira, constatou-se a necessidade da criação de um sistema descentralizado, hierarquizado e regionalizado que pudesse, em razão da proximidade com os cidadãos, melhor atendê-los. Foi então criado o Sistema Único de Saúde - SUS. 
Não obstante, o sistema do federalismo cooperativo está em crise, com reflexos diretos na prestação de serviços públicos de saúde à população, principalmente de baixa renda, que sofre com o péssimo atendimento proporcionado pelos órgãos estatais.

Por essa razão, a quantidade de demandas judiciais em desfavor dos entes públicos, tendo por objeto a prestação desses serviços, cresceu em números alarmantes, transferindo ao Poder Judiciário a tarefa de efetivar serviços, que deveriam ser prestados, obrigatório e automaticamente, pelo Poder Executivo.

Não obstante, o Poder Judiciário tem entendido, em decisões fundamentadas no art. 23 da Constituição Federal, que a responsabilidade pela prestação dos serviços de saúde é solidária entre a União, os Estados, o Distrito Federal e os Municípios.

Entretanto, tal entendimento esposado pelos órgãos judiciários acarreta incongruências jurídicas, tanto processuais quanto materiais, além de terem impactos sociopolíticos bastante negativos aos municípios brasileiros. Isso porque, como explanado, a irrestrita solidariedade dos entes da Federação na prestação dos serviços de saúde termina por dificultar, notadamente, a sobrevivência financeira da municipalidade, considerada a sua fragilidade orçamentária em relação aos Estados e à União.

Ademais, deve o Poder Judiciário ter em mente que os recursos do município são escassos, devendo ele, por isso, obediência ao princípio da reserva do possível, segundo o qual os direitos fundamentais sociais devem ser prestados, mas levandose em consideração a real necessidade do cidadão, a distributividade dos recursos e a efetividade do serviço, observando, ainda, o mínimo existencial, ou seja, as mínimas e dignas condições necessárias de sobrevivência, balizadas na necessidade do cidadão e nas possibilidades financeiras dos municípios. 


\section{REFERÊNCIAS BIBLIOGRÁFICAS}

ARRETCHE, Marta; MARQUES, Eduardo. Municipalização da saúde no Brasil: diferenças regionais, poder de voto e estratégias de governo. Ciência \& Saúde Coletiva, Rio de Janeiro, v. 7, n. 3, p. 455-479, 2002.

ASSIS, Gilmar de. SUS para todos: Breves reflexões jurídico-sociais. Avanços e desafios. In: Saúde: ALMEIDA, Gregório Assagra de; SOARES Jr., Jarbas; ASSIS, Gilmar de (coord). Belo Horizonte: Del Rey, p. 87, 2013.

BRASIL - STF - RE-AGR No 393175/RS, 2ª Turma, Rel. Min. Celso De Mello, DJ 02-02-2007.

ADI n 2472-8, Relator Ministro Maurício Correa, Data de julgamento: 11/11/2004. Disponível em: www.stf.gov.br.

ADI $n^{\circ}$ 3.305-DF, Relator Ministro Eros Grau, Data de julgamento: 13/09/2006.

Disponível em: www.stf.gov.br.

STA n 91, Relator Ministro Eros Grau, Data de julgamento: 26/02/2007. Disponível em: www.stf.gov.br.

STA-AgR 175/CE, Relator Ministro Gilmar Mendes. Disponível em: www.stf.gov.br.

DAIN, Sulamis. et al. Avaliação dos impactos de reforma tributária sobre o financiamento da saúde. In: NEGRI, B.; FERRATO, G. (Org.). Radiografia da Saúde: 2001. Campinas: Editora Unicamp, 2001, p. 233-288.

GADELHA, Carlos Augusto Grabois. et al. Saúde e territorialização na perspectiva do desenvolvimento. Ciência \& Saúde Coletiva, Rio de Janeiro, v. 16, n. 6, p. 3003-3016, 2011.

LEDUR, José Felipe. Os direitos fundamentais sociais. Porto Alegre: Livraria do Advogado, p. 89, 2009.

LIMA, Luciana Dias de. Conexões entre o federalismo fiscal e o financiamento da política de saúde no Brasil. Ciência \& Saúde Coletiva, Rio de Janeiro, v. 12, n. 2, p. 511-522, 2007.

MACHADO, José Angelo.; ANDRADE, Marta Leone Costa. Cooperação intergovernamental, consórcios públicos e sistemas de distribuição de cursos e benefícios. Revista de Administração Pública, Rio de Janeiro, v. 48, n. 3, p. 695-720, 2014.

MENDES, Eugênio Vilaça. (Org.). Distrito sanitário: o processo social de mudança das práticas sanitárias do Sistema Único de Saúde. São Paulo: Hucitec; Rio de Janeiro: Abrasco, 1993.

NEVES, Luiz Antônio; RIBEIRO, José Mendes. Consórcios de saúde: estudo de caso exitoso. Cadernos de Saúde Pública, Rio de Janeiro, v. 22, n. 10, p. 2207-2217, 2006.

PIOLA, Sérgio Francisco; FRANÇA, José Rivaldo Mello; NUNES, André. Os efeitos da Emenda Constitucional 29 na alocação regional dos gastos públicos no Sistema Único de Saúde no Brasil. Ciência \& Saúde Coletiva, Rio de Janeiro, v. 21, n. 2, p. 411-421, 2016.

RIBEIRO, José. Mendes; COSTA, Nilson do Rosário. Regionalização da assistência à saúde no Brasil: os consórcios municipais no Sistema Único de Saúde (SUS). Planejamento e Políticas Públicas, Brasília, DF, n. 22, p. 173-220, 2000. 
SARLET, Ingo Wolfgang. A eficácia dos direitos fundamentais. $11^{\text {a }}$ ed. Porto Alegre: Livraria do Advogado, p. 215, 2012.

SILVA, José Afonso da. Comentário Contextual à Constituição. $3^{\mathrm{a}}$ ed. São Paulo: Malheiros, p. 767, 2007.

TRAVASSOS, Claudia; OLIVEIRA, Evangelina X. G.; VIACAVA, Francisco. Desigualdades geográficas e sociais no acesso aos serviços de saúde no Brasil: 1998 e 2003. Ciência \& Saúde Coletiva, Rio de Janeiro, v. 11, n. 4, p. 975-986, 2006.

VIACAVA, Francisco; BELLIDO, Jaime G. Condições de saúde, acesso a serviços e fontes de pagamento, segundo inquéritos domiciliares. Ciência \& Saúde Coletiva, Rio de Janeiro, v. 21, n. 2 , p. $351-370,2016$.

VIANA, Ana. Luiza d'Ávila.; LIMA, Luciana Dias; FERREIRA, Maria Paula. Condicionantes estruturais da regionalização na saúde: tipologia dos Colegiados de Gestão Regional. Ciência \& Saúde Coletiva, Rio de Janeiro, v. 15, n. 5, p. 2317-2326, 2010. 